\title{
A Nouvelle Vague sob o ponto de vista do jornal O Metropolitano
}

\section{The Nouvelle Vague from the point of view of the newspaper $O$ Metropolitano Alessandra Souza Malett Brum}

O jornal O Metropolitano, órgão da União Metropolitana dos Estudantes (UME), com sede no Rio de Janeiro, foi palco nos anos 1950 e 1960 de diversos debates sobre política, economia, literatura, teatro, música popular e cinema. Depois de um período de interrupção, voltou a circular no dia 4 de janeiro de 1959 sob a direção de Paulo Alberto Monteiro de Barros (Artur da Távola), tendo como redator-chefe Carlos Diegues (Cacá Diegues). O Metropolitano tinha então uma tiragem de 170 mil exemplares semanais, sendo 47 mil veiculados junto com o Diário de Notícias, que ocupava o quinto lugar entre os matutinos cariocas

\footnotetext{
Alessandra Souza Malett Brum é doutora pelo Programa de Pós-Graduação em Multimeios, Instituto de Artes/Unicamp, e professora adjunta do bacharelado em Cinema e Audiovisual e do Programa de PósGraduação em Artes, Cultura e Linguagens do Instituto de Artes e Design da Universidade Federal de Juiz de Fora (UFJF), Minas Gerais, Brasil. Atualmente desenvolve a pesquisa A Nouvelle Vague sob a ótica de críticos/cineastas do Cinema Novo com apoio da Propesq/UFJF (alesbrum@yahoo.com.br).

Artigo recebido em 23 de dezembro de 2012 e aprovado para publicação em 9 de abril de 2013.
}

Est. Hist., Rio de Faneiro, vol. 26, no 51, p. 193-212, janeiro-junho de 2013. 
no período entre 1958 e 1960 (Barbosa, 2007). Em grau de importância política na época, segundo o jornalista Villas-Bôas Corrêa, o Diário de Notícias perdia apenas para o Correio da Manhã: "Se vocês quiserem uma hierarquia, é o seguinte: havia mais ou menos 17, 18 jornais no Rio. Certamente, disparado, o Correio da Manhã era o mais importante, com mais peso político; o Diário de Notícias era o segundo, pela respeitabilidade. Era um jornal mais duro, menos malicioso" (Corrêa apud Barbosa, 2007: 156).

$\mathrm{O}$ apoio do Diário de Notícias à UME na distribuição de $O$ Metropolitano demonstrava que o jornal feito por estudantes era maduro e alinhado a seus preceitos ideológicos. A parceria entre o Diário de Notícias e a UME permitiu também ao jornal $O$ Metropolitano uma visibilidade e uma inserção junto a um público muito mais amplo, não restrito apenas aos estudantes. Aliás, essa era mesmo a pretensão do jornal, como afirmou seu diretor Paulo Alberto Monteiro de Barros em entrevista ao Diário de Notícias a poucos dias do início da sua circulação como encarte do matutino.

Não pretendemos fazer um jornal de âmbito exclusivamente estudantil. Muito ao contrário, desde que nossa pretensão é fazer um jornal para todos, dando conta à sociedade da qual nossa classe é parte ativa e atuante, das nossas aspirações, do que fazemos e do que queremos e do que precisamos. "O Metropolitano" será um jornal feito por estudantes para o grande público. (...) Outro aspecto para o qual desejo chamar a atenção de todos refere-se à nossa orientação. Seremos equidistantes de todas as ideologias e não nos filiaremos a nenhuma corrente partidária, mesmo porque nosso objetivo não é fazer política e sim um jornal (1 de janeiro de 1959).

A afirmação do diretor de que $O$ Metropolitano era um órgão apolítico é curiosa, já que ele afirmava também que o jornal atuaria ativamente como um veículo que falaria do que a classe estudantil fazia, queria e precisava, deixando implícito que o órgão iria se posicionar diante de questões de interesse do país e dos estudantes. Havia, portanto, uma posição política (não partidária) e ideológica, e isso pode ser observado ao longo dos anos de existência de $O$ Metropolitano.

Os assuntos relacionados à política nacional sempre foram priorizados pelo jornal, dentro de uma abordagem nacionalista-desenvolvimentista com profunda influência do Instituto Superior de Estudos Brasileiros (ISEB), muito próxima do pensamento dos isebianos Guerreiro Ramos, Álvaro Vieira Pinto e Nelson Werneck Sodré, todos colaboradores assíduos de O Metropolitano. Temas como Petrobras, Companhia Vale do Rio Doce, Companhia Siderúrgica Nacio- 


\section{A Nouvelle Vague sob o ponto de vista do jornal O Metropolitano}

nal sempre estiveram presentes nas páginas do jornal, fazendo coro a um movimento político pró-reformas de base que reivindicava mudanças nas estruturas da economia, perspectiva, aliás, também presente no interior do ISEB nos anos 1960 .

A posição ideológica nacionalista foi expressa na primeira página de $O$ Metropolitano em julho de 1959, por ocasião da realização do XXII Congresso Nacional dos Estudantes, sob o título Manifesto ao povo. Dizia o Manifesto:

Consideramos que uma ideologia (?) nacionalista é a que nos serve neste momento. Mas entendemos também que o nacionalismo é uma política de ação e um programa a ser cumprido. O nacionalismo como ideologia, aquele que nós traduzimos como o nosso, é a ideologia que serve a um país em determinado estágio de seu desenvolvimento. Não é o nacionalismo fascista das grandes potências, mas sim a ideologia que rompe com os processos de intervenção e dominação estrangeiras. ${ }^{1}$

O Metropolitano era portanto um jornal muito envolvido com as questões relativas à política nacional, como podemos observar em sua estrutura editorial. $\mathrm{O}$ jornal era editado com seis páginas, três delas dedicadas à política e à economia, uma a variedades, uma aos esportes universitários e uma às artes, com colunas de literatura, música popular, teatro e cinema.

Em 1960 a direção de O Metropolitano foi assumida por Carlos Diegues, que em novembro a transmitiu a Cesar Guimarães, o qual por sua vez prometeu inaugurar uma nova fase no jornal. Guimarães reorganizou o jornal dentro de um esquema empresarial, aumentando o número de integrantes da equipe a fim de suprir a necessidade de crescimento de $O$ Metropolitano. O expediente do jornal comprovava essa profissionalização e ampliação da equipe, com funções claramente definidas por setor de atividade: de cinco cargos em 1959, quando o jornal voltou a circular, passou-se então para 19 cargos.

Seguindo o critério de eleição da diretoria da UME, que era anual, em meados de 1961 Nelson José Pompéia assumiu a direção do jornal. O novo cenário político brasileiro dificultou em muito a vida de $O$ Metropolitano, já que muitos dos patrocinadores desapareceram pelo fato de o jornal adotar uma posição cada vez mais assertiva e crítica em prol das reformas de base. Incapacitada financeiramente, tendo inclusive o telefone da redação cortado por falta de pagamento, a direção de $O$ Metropolitano se viu obrigada a tomar algumas atitudes para viabilizar a circulação do jornal. Assim, em agosto de 1961, o jornal passou a circular somente aos sábados junto com o Diário de Notícias e em formato de ta- 
bloide. ${ }^{2}$ Decidiu-se dessa forma tomar "medidas de economia, ditadas em consequência do grande aumento do preço do papel de imprensa, bem como antecipar a sua saída de um dia, quando é menor a tiragem de todos os órgãos de imprensa. $\mathrm{O}$ importante, porém, é que aqui estamos, mudados apenas formalmente...” (Editorial, 20 de agosto de 1961).

As dificuldades não estavam restritas às questões financeiras: a edição do dia 2 de setembro de 1961 saiu com apenas duas páginas, e a justificativa apontava para a nova conjuntura política do Brasil. Com a renúncia do então presidente Jânio Quadros e com os ministros militares tentando impedir que o vice-presidente João Goulart assumisse a presidência da República, os estudantes foram uma força de resistência na tentativa de impedir um golpe de Estado, o que os tornou alvo da polícia de Estado. No editorial dessa edição os estudantes esclareciam que a redação estava sendo silenciada e denunciavam: "Os últimos acontecimentos, ou seja, a invasão pela polícia da sede da UNE, prisão do Marechal Lott, envio de esquadra ao Rio Grande do Sul, etc., demonstram claramente o desenvolvimento de um golpe militar" ( 2 de setembro de 1961, p. 13).

Em novembro de 1961, o editorial do jornal O Estado de S. Paulo acusou O Metropolitano de servir ao Partido Comunista, além de não tratar de assuntos estudantis, razão de sua existência. Esse cenário político obrigou muitas vezes $O$ Metropolitano a sacrificar a página dedicada às artes. Apesar de todos esses contratempos, $O$ Metropolitano procurou manter suas edições dentro de uma certa normalidade.

Portanto, era nesse contexto político, econômico e ideológico que a coluna de cinema se inseria no jornal, e é também dentro dessa perspectiva que procuramos compreender o olhar voltado pelos articulistas para o novo cinema francês que emergia sob o título de Nouvelle Vague. É nesse cenário, de 1959 a 1962, período aqui proposto para a análise do olhar de $O$ Metropolitano sobre o movimento da Nouvelle Vague, que podemos perceber alterações substanciais na atividade cinematográfica brasileira e também na postura da crítica diante do nosso cinema. Destacamos nesse contexto a publicação do livro Introdução ao cinema brasileiro de Alex Viany em 1959; a II Jornada de Cineclubes Brasileiros e a realização da I Convenção Nacional da Crítica Cinematográfica em 1960; a homenagem ao cinema brasileiro na VI Bienal de São Paulo em 1961; e ainda uma produção de filmes nacionais para além das chanchadas, que aos poucos foi se tornando objeto de análise dessa crítica tão habituada a escrever sobre a produção cinematográfica estrangeira.

A coluna de cinema de $O$ Metropolitano, nos dois primeiros meses de 1959, colocou-se de maneira muito tímida, sem críticas de filmes, apenas com notas sobre os acontecimentos cinematográficos da cidade. O responsável pelos 
comentários de cinema era Dejean Magno, presidente do Grupo de Estudos de Cinema (GEC) da UME. Mas já em março de 1959, David E. Neves passou a assinar a coluna, e foi a partir desse momento que ela tomou corpo e aos poucos ganhou destaque no jornal. Em meados de 1960, David Neves passou a dividir a tarefa com Sérgio Augusto, com algumas colaborações esporádicas de Carlos Diegues e também de Paulo Perdigão. Vale ressaltar que dado o momento bastante vigoroso para a arte cinematográfica, o tema cinema não se restringiria apenas à coluna na página de artes, mas ocuparia outras páginas do jornal, com algumas matérias chegando a tomar a página inteira. ${ }^{3}$

Para essa análise tomamos como referência os artigos, comentários e matérias de David Neves, Sérgio Augusto e Carlos Diegues, todos jovens imberbes, mas que nos anos seguintes desempenhariam papel central para o cinema brasileiro. David Neves e Carlos Diegues ${ }^{4}$ teriam destacada participação na formação do Cinema Novo - não por acaso O Metropolitano foi considerado um dos núcleos de gestação desse movimento de renovação do cinema brasileiro. Já Sérgio Augusto atuaria no campo da crítica de cinema e também como repórter, redator e editor de jornais como o Correio da Manhã, Fornal do Brasil e Folha de S. Paulo, nas revistas OCruzeiro e Veja e nos semanários alternativos Pasquim e Opinião..$^{5}$

O material aqui reunido nos permitiu estabelecer três fases de um processo de maturação e compreensão do movimento cinematográfico da Nouvelle Vague, que surgia na França com a promessa de inaugurar uma nova linguagem cinematográfica e despertava o olhar atento dos críticos brasileiros. Chamamos a primeira fase de "primeiras impressões" (de 1959 a meados de 1960), a segunda fase de "o movimento e o desencanto" (de meados de 1960 a meados de 1961), e a terceira fase de "o que interessa somos nós" (meados de 1961 a 1962).

\section{Primeira fase: primeiras impressões (de 1959 a meados de 1960)}

As primeiras notícias sobre o novo cinema francês apareceram nas páginas de $O$ Metropolitano por ocasião do Festival História do Cinema Francês, realizado pelo Museu de Arte Moderna (MAM) do Rio de Janeiro a partir de julho de 1959. Tratava-se de uma retrospectiva com exibições de Georges Méliès, Max Ophuls, Abel Gance, Marcel Carné, Jean Renoir, Jean Epstein, Robert Bresson, apenas para citar alguns nomes. O festival foi tema constante da coluna de cinema escrita por David Neves, que passava suas impressões a cada programa por ele assistido. Em nenhum momento a expressão Nouvelle Vague ou mesmo "novo cinema francês" foi comentada por Neves, apesar de constar no catálogo produzido para o festival um artigo dedicado à Nouvelle Vague. ${ }^{6}$ 
De qualquer modo, lembramos que a expressão Nouvelle Vague começou a aparecer na imprensa francesa referindo-se especificamente à nova produção cinematográfica a partir de fevereiro e março de 1959, e ganhou força em maio seguinte, por ocasião da seleção de Os incompreendidos, de François Truffaut, para o Festival de Cannes. Em agosto do mesmo ano, o jornal Le Monde realizou um debate sob o título L'avenir du cinéma français reunindo alguns cineastas em atividade na época a fim de discutir esse novo cinema francês. Isso significa que o evento realizado no Rio de Janeiro ainda não trazia filmes representativos da Nouvelle Vague, o que de certo modo explica o silêncio de David Neves sobre o assunto.

A primeira vez que o tema apareceu na coluna de cinema de $O$ Metropolitano foi no dia 27 de setembro de 1959, sob o título Nouvelle Vague. A empreitada não coube ao responsável pela coluna, David Neves, e sim ao interino Carlos Diegues. Nesse artigo, Diegues considerava que "a síntese da nouvelle vague estaria na própria definição de anticinema: a valorização temática intimista, substituindo os valores funcionais (imagem, câmara, montagem etc.) pela supervalorização, a hipertrofia da descrição meio social, meio psicológica, meio ética.” Ressaltava ele que os jovens cineastas franceses procuravam caminhos próprios, mas sem compromisso manifesto, destacando no conjunto de novos cineastas Louis Malle, Edouard Molinaro, Claude Chabrol, Michel Boisrond e Roger Vadim. Carlos Diegues terminava o artigo deixando claro que sua análise dizia respeito aos filmes exibidos no Brasil e que os outros cineastas dessa nova geração continuavam inéditos por aqui.

Duas semanas depois, em 11 de outubro, sob o título fean Renoir e a Nouvelle Vague, David Neves faria considerações acerca do artigo de Carlos Diegues. David Neves discordava de Diegues quanto à Nouvelle Vague, principalmente no que dizia respeito às inovações estéticas, questionando o subjetivismo da nova escola. Dizia Neves: "Por mais estranho que possa parecer, a atualidade das inovações de jovens cineastas franceses remonta à inspiração do velho mestre", referindo-se a Jean Renoir. Para ele, o que havia no novo cinema francês era um "comodismo visual que não racionaliza nada". Essas primeiras impressões já demonstravam que o tema Nouvelle Vague seria polêmico. Mas, já nesse artigo, David Neves nos direciona a pensar em duas questões que estariam na ordem das discussões sobre o movimento francês e, por que não dizer, sobre o próprio cinema brasileiro que começava a despontar: uma diz respeito à forma, que era a inovação estética, e a outra diz respeito ao conteúdo, o tratamento narrativo pelo viés da subjetividade, alvo de crítica por parte dos colunistas.

Em janeiro de 1960, David Neves foi a Belo Horizonte a fim de participar e realizar a cobertura jornalística da II Jornada de Cineclubes. Como parte integrante das atividades da jornada foi exibido pela primeira vez no Brasil o fil- 
me Hiroshima, mon amour, de Alain Resnais. Em matéria publicada em O Metropolitano sobre a jornada, David Neves reclamou da organização do evento pelo fato de não terem permitido um debate acerca do novo filme de Resnais. Dizia ele:

Se durante a prestação de contas dos cineclubes mais dedicados, ficávamos satisfeitos de conhecer-lhes o sistema de projeção, estudos, debates e análises de filmes, aqui, ao vivermos um momento de intensa vibração cinematográfica, não se propõe uma dissecação coletiva do filme polêmico que é Hiroshima, mon amour e limitamo-nos mais tarde a escutar, semiaborrecidos, a mais uma palestra sobre o tema ultrarrepisado que é o da origem da sétima arte ${ }^{7}$ (31 de janeiro de 1960).

Após esse comentário, David Neves se dedicava a falar sobre o filme $\mathrm{Hi}$ roshima, mon amour, que muito o inquietou:

O filme de Resnais não nos pervez (sic) (os membros da Jornada puderam desfrutar de uma nova visão, na manhã de segundafeira) um estudo coerente. Diremos somente da impressão indefinida que tivemos, na qual se inclui talvez um fator favorável: o fato de ser um filme onde a análise introspectiva consegue realmente ser, por vezes, correlata à imagem. Há, porém, passagens extraídas de documentários sobre a explosão nuclear em Hiroshima, cujo insólito parece querer repetir o sucesso de Nuit et brouillard e não oculta o lado tipicamente pacifista do autor, mas um pacifismo manifestado em momentos impróprios (não valeria o paralelismo apresentado, mesmo sendo um filme fixador de momentos interiores) e que perturbará na certa o espectador menos avisado. Voltaremos ao assunto.

Foi com Hiroshima, mon amour que David Neves se sentiu instigado a realizar um estudo mais detido sobre esse novo cinema francês, reconhecendo no filme de Resnais sua inegável inovação estética. Apesar de avisar que em breve voltaria ao assunto Hiroshima, mon amour, David Neves só faria uma análise detida em agosto de 1960, momento em que o filme entrou em cartaz no Brasil.

No dia 12 de junho de 1960, Carlos Diegues e David Neves publicaram juntos a matéria "Roteiro para a história do cinema". Tratava-se de um resumo esquemático das aulas de "Interpretação da história do cinema" ministradas por 
eles em alguns colégios do Rio de Janeiro, cursos que foram organizados pela $\mathrm{Fe}$ deração dos Cineclubes do Rio de Janeiro. Dentro do tema cinema contemporâneo, eles destacavam a Nouvelle Vague acompanhada dos seguintes tópicos:

a linguagem clássica; o lirismo; o comodismo visual; a exaltação ao amor; êxitos esparsos (Vadim, cena culminante de Les amants, independência quanto à produção); Hiroshima, mon amour, de Alain Resnais, como tentativa de inovação narrativa, inalterada desde Welles; Robert Bresson mestre de toda a Nouvelle Vague (o cinema-literatura).

Até aquele momento, junho de 1960, fase que consideramos ser a das primeiras impressões de um movimento, o que balizava as primeiras análises eram os poucos filmes que aqui chegaram via festival e a leitura das revistas francesas, sobretudo a Cahiers du Cinéma. A Nouvelle Vague ainda não havia correspondido às expectativas dos críticos brasileiros, que consideravam que a publicidade em torno do movimento era maior que a efetiva qualidade dos filmes.

\section{Segunda fase: o movimento e o desencanto (de meados de 1960 a meados de 1961)}

Em julho de 1960 foi realizado no MAM um ciclo de cinema francês dedicado aos filmes da Nouvelle Vague que posteriormente seriam lançados em alguns cinemas do Rio. Nesse ciclo foram programados sete filmes: Os libertinos (Les dragueurs, Jean-Pierre Mocky); Os incompreendidos (Les 400 coups, François Truffaut); Hiroshima, meu amor (Hiroshima, mon amour, Alain Resnais); Os primos (Les cousins, Claude Chabrol); Águias indomáveis (Normandie-Niémen, Jean Dréville); A ponte (Die Brücke, Bernhard Wickl); Arquimedes, o vagabundo (Archimède, le clochard, Gilles Grangier). Dessas estreias, Os primos (Les cousins), de Claude Chabrol, foi tema do artigo de David Neves em O Metropolitano escrito logo após a exibição em 10 de julho.

Não fossem algumas passagens de efeito puramente literário que resultam bastante enfadonhas relembrando também o Bergman de Sorrisos, e o parti-pris adverso que tomamos face à Nouvelle Vague, pelos exemplos que chegaram até nós, e face a Chabrol com aquele início desanimador, poderíamos ter assistido a esta fita com espírito bem mais condescendente, o que por certo se traduziria aqui em palavras de maior 


\section{A Nouvelle Vague sob o ponto de vista do jornal O Metropolitano}

louvor. O filme, com exceções que já apontamos, é digno de certo registro (10 de julho de 1960).

Aqui David Neves demonstra claramente seu desânimo frente ao novo cinema francês que até aquele momento não mostrara a que tinha vindo. Nesse particular, havia uma certa concordância com as ideias de Sérgio Augusto, que, a partir de meados de 1960, passou a dividir a coluna de cinema com Neves. Por diversas vezes sobraram elogios à antiga geração de cineastas franceses por parte de ambos os críticos. Aliás, a questão da juventude, que estava também no cerne da Nouvelle Vague, não foi em nenhum momento ponto de destaque por aqui; ao contrário, tanto para David Neves quanto para Sérgio Augusto, o caminho desses cineastas não era um caminho próprio, como havia apontado Carlos Diegues naquele artigo de 1959. Era, na realidade, um retorno ou uma referência aos cineastas clássicos franceses já consagrados, como René Clair ou Jean Renoir. Sérgio Augusto, por exemplo, apontava René Clair como "uma das maiores figuras que ainda labutam dentro de um cinema por vezes decadente, e é a maior personalidade de todo o cinema francês" (17 de julho de 1960).

Em agosto de 1960, depois de assistir pela segunda vez a Hiroshima, mon amour, David Neves escreveu, como havia prometido, o artigo Hiroshima-Nevers: um itinerário (7 de agosto de 1960), dedicado ao filme de Alain Resnais. Nesse artigo, procurava dialogar com os críticos que viam em Hiroshima, mon amour um filme inaugurador de uma nova linguagem. Hiroshima, mon amour seria ou não um divisor de águas na história do cinema depois de Cidadão Kane? O filme de Orson Welles ocupava até então entre a crítica brasileira o grau mais alto na escala de importância de filmes que consolidaram o cinema como arte. Com o aparecimento de Hiroshima, mon amour, a posição de destaque de Cidadão Kane começava a ser questionada. Para alguns críticos, o filme de Welles chegava mesmo a perder o posto para o novo filme de Resnais, como vemos pelo artigo de José Lino Grünewald publicado no fornal de Letras em junho de 1960 (Brum, 2009). David Neves se posicionava contrariamente a essa postura de alguns críticos que queriam dar a Hiroshima, mon amour o título de fundador de uma nova linguagem. Porém mesmo não compactuando com a ideia de que Hiroshima, mon amour fosse um inaugurador de linguagem, David Neves não deixava de reconhecer o caráter inusitado da obra de Resnais:

Não há dúvida de que estamos diante de uma realização sui generis (...) Obra-prima ou filme desprezível, acreditamos que a polêmica despertada de imediato nos lugares onde passa já é, em si, fato salu- 
tar e prova cabal de seu mérito. (...) Que estas palavras iniciais abram as portas para melhores tentativas de apreensão deste fenômeno que sacode o mundo cinematográfico moderno.

Com os filmes do novo cinema francês chegando por aqui, era o momento de rever ou reafirmar posições, como fez por exemplo David Neves no artigo sobre Hiroshima, mon amour. Foi o que fez também Carlos Diegues acerca do movimento Nouvelle Vague em 14 de agosto de 1960, 11 meses após seu primeiro artigo sobre o assunto em $O$ Metropolitano.

Nesse novo texto, intitulado Nouvelle Vague, Carlos Diegues relembrava suas posições no primeiro artigo, dando destaque ao fato de a nova geração colocar em segundo plano os elementos funcionais da linguagem cinematográfica para poder "expressar os problemas de um homem", e completava: "na realidade, estavam (os cineastas) de tal modo tomados pelo drama íntimo de seus personagens que sua implicação social servia apenas como falso engajamento, numa postura artificial, primária e, de certo modo, infantil". Naquela época ele colocava Vadim e Alexandre Astruc como exceções dentro do contexto da Nouvelle Vague, e agora mais um autor podia ser incluído: Alain Resnais com Hiroshima, mon amour. Para Carlos Diegues:

A segunda visão de conjunto dos cineastas da "nouvelle vague" não altera muito os conceitos emitidos anteriormente em razão de suas obras passadas. A linguagem é a mesma, o verbo fílmico não se altera, ainda prejudicado pelas falsas composições. O vazio experimental dos filmes da nouvelle vague chega ao paroxismo de um Jean Pierre Mocky preocupado em fundamentar a pobreza de sua postura, num alegorismo romântico que vai do fácil ao ridículo.

O filme de Chabrol, Os primos, ganhou destaque no quesito renovação de linguagem, uma "audácia formal" que Carlos Diegues percebia existir com a chegada da segunda leva de filmes exibidos por aqui. Por outro lado, em relação à temática dos filmes da Nouvelle Vague, e à ênfase nas questões subjetivas dos personagens, Carlos Diegues comentava:

A pseudocrítica social de todos os filmes em pauta prejudica-se pela exploração de um mito suficientemente superado por toda uma literatura passadista - o do conflito homem-sociedade. Este, quase sempre, é encontrado em suas formas de relações grupais, sem 


\section{A Nouvelle Vague sob o ponto de vista do jornal O Metropolitano}

uma compreensão do fenômeno social em sua totalidade. A pesquisa psicológica, ela mesma, não chega a se realizar, comprometida e prejudicada pela extensão de elementos que alienam o tema da pesquisa (o alegórico, em Mocky; o dramático, em Chabrol, e assim por diante). Neste ângulo o impasse da nouvelle vague permanece e promete muito pouco uma superação.

Nesse artigo, a questão do engajamento político ganha força, mas Carlos Diegues parece procurar um sentido para essas experiências de linguagem, que para ele não deixavam de ser válidas. Ele terminava o artigo dizendo que era preciso aguardar um pouco mais, afinal não se podia esperar de todos os cineastas a profundidade que Eisenstein e Orson Welles tiveram. Vale ressaltar que ele não havia assistido ao filme Os incompreendidos de François Truffaut quando escreveu sua análise.

Na semana seguinte, em 21 de agosto de 1960, foi a vez de Sérgio Augusto expor suas opiniões sobre essa nova leva de filmes exibidos no ciclo de cinema francês dedicado à Nouvelle Vague realizado pelo MAM. Ele escreveu o artigo "Ford, comédias e cinema francês" e fez curtos comentários sobre cada um dos filmes a que assistira “(d)essa 'vague' que só tem feito onda e nada mais”. Dos sete filmes exibidos, não assistira apenas a Os libertinos. Seu maior destaque era para Os incompreendidos de François Truffaut, que, para ele, pelo fato de ter sido precedido de muitos elogios, criara a expectativa de ser uma obra-prima. Dizia Sérgio Augusto:

Truffaut, com os demais colegas seus desse 'movimento', apenas utiliza os ensinamentos apreendidos nos cineclubes e cinematecas. Então por que chamá-los de revolucionários. Ainda há, o que é mais grave, os que acusam a obra de Truffaut de ser plágio de uma outra de Vigo, Zero de conduite...

Com relação ao filme Hiroshima, mon amour, Sérgio Augusto, na mesma linha de David Neves, afirmava que "não é, absolutamente, a tão propalada pós-wellesiana", mas também, como David, demonstrava certa inquietação com a novidade narrativa, já que confessava ser necessário vê-lo duas ou três vezes mais.

Mas foi em outubro de 1960 que Sérgio Augusto realmente expressou com mais objetividade e clareza sua opinião sobre o movimento da Nouvelle Vague. Seu artigo foi uma resposta à carta de um leitor acerca de seus comentários sobre a Nouvelle Vague na edição anterior. A citação é longa, mas importante, por refletir bem o pensamento de Sérgio Augusto: 
...muitos críticos de respeito e confiança também atacaram a NV, e será que podemos afirmar, categoricamente, que eles nada entendem do assunto? Pessoalmente, como o afirmei num artigo sobre René Clair (O Metropolitano - 17-7-1960), achamos louvável (admirável mesmo) a intenção de renovação que passa pelas cabeças destes neófitos da "nouvelle vague", mas verdade é que não encontramos, em nenhuma dessas obras pertencentes ao movimento, qualidades que as possam elevar à altura que muitos as têm colocado. Há exceções, naturalmente, $\mathrm{e}$ podemos citar: "Un condanné à mort s'est échappé", "Et Dieu créa la femme", "Sait-on jamais", mas pertencem Bresson e Vadim ao grupo da NV? Se eles fazem, e se sentem, parte dessa movimentação, tanto melhor, pois já terá a NV, em seu "dossier", algo a seu favor. O plágio (incontestável) de Truffaut em "Les 400 coups", o meio-termo em que ficou Mocky com seu "Les dragueurs" (por nós assistido mais tarde), a literatura emprestada de Duras a Resnais, a má assimilação d"O método" por Chabrol, a vigarice de outros como Félix e Camus servem de substrato à nossa afirmação: a "onda" que essa "vague" vem causando, uma "onda" que poderá se transformar em tormenta e trazer algo novo ao cinema, até agora nada despertou em nós a não ser expectativa.

Após essa resposta ao leitor, Sérgio Augusto escreveu no mês seguinte (20 de novembro de 1960) o artigo "Cinema moderno e Nouvelle Vague". Esse foi o primeiro artigo de Sérgio Augusto especificamente sobre o tema; todos os outros foram comentários curtos e diretos, mas contundentes. Nesse momento, a discussão em torno da Nouvelle Vague já movimentava toda a crítica cinematográfica. Sérgio Augusto realizou então uma análise de mais fôlego sobre o assunto, dando destaque a quatro cineastas: Chabrol, Truffaut, Resnais e Malle. Para Sérgio Augusto fora com Cidadão Kane de Orson Welles que o cinema se tornara moderno, que o cinema dera um passo a mais. Essas considerações sobre o cinema de Orson Welles demarcavam sua posição contrária à ideia de a Nouvelle Vague ter proporcionado uma inovação na linguagem cinematográfica. Na realidade, não havia nenhuma alteração em relação aos seus comentários anteriores. Quanto à questão de a Nouvelle Vague ser ou não um movimento cinematográfico, Sérgio Augusto dizia: "A 'nouvelle vague' é uma realidade, que, embora capenga, existe. Desde o grito dado por Astruc, em seu Le rideau cramoisi, até os mais recentes filmes vague nada se viu além da rotina e da boa vontade desses realizadores da nova geração."

Como de costume, no início de cada ano, a coluna de cinema de $O$ Metropolitano se dedicava a destacar os melhores filmes do ano que findara. Pela impossibilidade de um consenso entre os críticos David Neves e Sérgio Augusto, 


\section{A Nouvelle Vague sob o ponto de vista do jornal O Metropolitano}

como informou o jornal, em 1961 duas listas, e não uma, foram publicadas. No dia 15 de janeiro foi publicada a lista dos melhores filmes do ano de David Neves $^{8}$ e no dia 22 a lista de Sérgio Augusto. ${ }^{9}$ Em relação à Nouvelle Vague, David Neves dizia: "as obras-primas que se esperavam de uma nouvelle vague camuflada pela propaganda dos Cahiers du cinéma não confirmaram o êxito esperado".

A expectativa em torno da Nouvelle Vague, amplamente difundida pela revista francesa Cahiers du cinéma e acompanhada pelos críticos brasileiros, foi frustrada com a exibição dos primeiros filmes do movimento.

\section{Terceira fase: o que interessa somos nós (meados de 1961 a 1962)}

No final de abril de 1961 estreou no Brasil Acossado (À bout de souffle) de Jean-Luc Godard. Em 21 de maio David Neves escreveu o artigo intitulado "Um filme e um conflito" sobre esse filme da Nouvelle Vague que considerou "simples e bom". Dizia Neves: "do que temos visto, no panorama da nouvelle vague ele pode ser considerado filme de exceção por ser a) acessível a todas as categorias de espectador, $b$ ) realmente portador de um esboço de renovação da narrativa fílmica". Para David Neves Acossado era um trabalho de equipe que renovava a linguagem cinematográfica pela simplicidade e pela contribuição para as escolas realistas. Um filme, portanto, para ser estudado. Aproveitando a ocasião, David Neves traduziu e publicou o texto Montagem de meus amores de Jean-Luc Godard, como subsídio para se entender o processo desse cineasta. Esse foi o único filme da nova safra francesa que empolgou David Neves, e não por acaso ele o considerava uma exceção na lista de filmes da Nouvelle Vague. Aliás, essa era uma prática entre esses críticos, que, ao encontrar algum elemento inovador de linguagem nos filmes pertencentes à Nouvelle Vague, o consideravam exceção, como se não fizesse parte do movimento. O curioso dessa prática vem a ser o fato de esses críticos, desde o início, procurarem compreender o novo cinema francês dentro de uma ótica de movimento, como um grupo de novos cineastas com ideias e pensamento estético convergente.

O filme de Jean-Luc Godard não mereceu comentários mais aprofundados nem de Carlos Diegues, nem de Sérgio Augusto. É importante lembrar que foi nesse momento que o cenário político brasileiro começou a se desestabilizar, e os setores da esquerda, o que incluía os estudantes, se engajaram politicamente. A UNE iniciou seu processo de concepção do Centro Popular de Cultura, um projeto político-cultural com a finalidade de politizar o público estudantil por meio da arte. Com relação ao cinema brasileiro, esse foi um momento de grande vigor. Os críticos de cinema, muitos deles futuros cineastas, voltaram seu olhar 
para a produção nacional e, sobretudo, para a construção de um projeto de cinema para o Brasil. A busca de um projeto próprio, com a nossa cara, era o horizonte a ser seguido, como podemos apreender do artigo de Carlos Diegues "Perspectivas para o cinema brasileiro" (2 de julho de 1961), que fazia um diagnóstico de nossa cultura cinematográfica. Dizia Diegues:

A adolescência de nossa cultura cinematográfica ainda não permitiu a criação, a audácia de uma nova técnica, mas pretende chocar com a utilização de instrumentos doados pelos mais "bem aceitos" mestres modernos. Daí, três linhas vão sendo exploradas à guisa de se "estar em dia com o cinema": o neorrealismo italiano, o neoexpressionismo via Ingman Bergman e o novo cinema americano. A curta vista, seriam estas suas fontes de informação mais diretas. Paralelamente, há a influência de uma escola crítica como a do "Cahiers du cinéma", ou o cineclubismo mal informado, os mitos históricos etc. E, ainda, a longo prazo, toda uma história do cinema universal comandada por estas influências imediatas.

Para Diegues, essa nossa condição levava à completa paralisia na linguagem do cinema brasileiro porque estávamos sempre diluindo essas influências estrangeiras em nossa maneira de fazer cinema. Nota-se que o movimento da Nouvelle Vague não era um projeto de cinema "bem aceito", já a crítica sim, através da Cahiers du cinéma. Nessa mesma linha seria a entrevista realizada por $O$ Metropolitano com Carlos Diegues sobre seu primeiro filme, Domingo, sob o título "Cinema Novo" (30 de julho de 1961). Questionado sobre o cinema novo no Brasil, Diegues respondeu:

É preciso ordenar as questões básicas que se colocam para o cinema moderno, e respondê-las com conteúdo e não com efeitos publicitários. É evidente que os jovens estarão obviamente muito mais abertos a uma experiência nova do que aqueles que já deixaram vencer pelas formas e fórmulas. Mas idade não é critério para o julgamento do bom cineasta, nem o novo é bom porque é novo. Eisenstein não é novo e continua sendo bom. Para nós, o novo que se identifica com o bom é aquele que, em cinema, retoma as linhas fundamentais de uma pesquisa de linguagem para a arte cinematográfica, linguagem específica e própria, e soma a esta pesquisa um compromisso com seu tempo e lugar. Daí, não cremos ser pretensão afirmar que procuramos a linguagem cinematográfica brasileira. Pode ser que "Domingo" não tenha consegui- 


\section{A Nouvelle Vague sob o ponto de vista do jornal O Metropolitano}

do isso. É até mais provável que não, principalmente se tratando de nossa primeira experiência mais séria e comprometida com aquela dupla formulação. Mas será uma tentativa de chegar lá.

O cinema brasileiro ia aos poucos se impondo, não apenas a partir de um pensamento crítico, mas sobretudo no fazer cinematográfico. Exemplo disso foi a homenagem ao cinema brasileiro na VI Bienal de São Paulo, em 1961, com a exibição de curtas-metragens de novos realizadores que mais tarde formariam o grupo do Cinema Novo, como Aruanda (1960) de Linduarte Noronha, Arraial do Cabo (1959) de Paulo César Saraceni e Mário Carneiro, O Mestre de Apipucos (1959) e O Poeta do Castelo (1959), ambos de Joaquim Pedro de Andrade. Esse novo momento do cinema brasileiro foi registrado por Francisco Luiz de Almeida Salles no artigo "Novos realizadores do cinema do Brasil" publicado no dia 21 de outubro de 1961:

E pode-se dizer que, no conjunto, a homenagem não significou apenas uma forma de confiança e de estímulo, mas uma abertura de esperança num cinema brasileiro mais sério e, principalmente, num cinema brasileiro não alienado. Porque o que se espera do novo cinema brasileiro é menos acertos técnicos e estéticos, menos demonstração de que podemos fazer filmes no nível de exigências de outros países, do que uma ideologia, uma tomada de posição em função de uma problemática social e humana brasileira, um estilo de criação que decorra dessa problemática e exprima a nossa forma de ver e sentir a realidade.

Esse pensamento de um cinema "não alienado" que trouxesse em sua essência a cara do Brasil foi tomando corpo na nova geração de cineastas e também nas análises dos críticos que passaram a olhar de maneira mais atenta às produções realizadas por aqui. No caso de $O$ Metropolitano, essa era uma questão que sempre esteve na ordem do dia, como procuramos demonstrar aqui.

O tema da Nouvelle Vague seria retomado por David Neves apenas em novembro de 1961, quando publicou o artigo "Os primitivos da Nouvelle Vague" (18 de novembro de 1961). Nesse artigo David Neves ressaltava a sinceridade autoral e até um certa falta de experiência de Jean-Luc Godard, referindo-se a dois curtas-metragens (Tous les garçons s'appelent Patrick e Charlotte et son Fules) realizados por ele. Sobre os curtas, afirmava David:

...com os naturais vícios e defeitos provocados pela falta de intimidade de Godard com a nova linguagem uma visão do mundo 
que mais tarde seria "passada a limpo" em $\grave{A}$ bout de souflle (eis o sentido do primitivismo: a universalidade vem sob a forma de imperfeição e sobressalto - característica godardiana por excelência).

Era esse "primitivismo" que David Neves encontrava na obra de Godard que o interessava como renovação de linguagem. Um cinema de produção artesanal, realizada com equipe mínima e baixo orçamento, propiciada por câmeras mais leves e películas mais sensíveis que permitiam tirar o cinema dos estúdios e redescobrir as ruas. Em Acossado os atores interagem com os cenários naturais impregnando os planos com um registro documental, o que era muito inovador e explicava o interesse de David Neves pelos filmes de Godard. Isso era o que permitia a Neves afirmar que, com os filmes que chegaram aqui naqueles últimos três anos, já se podia ter uma visão das características da Nouvelle Vague, que, "embora anacrônicas, agrupam-se entre o que de mais interessante e de mais sincero os jeunes Turcs fizeram em prol da sétima arte".

No final do ano de 1961, O Metropolitano dedicou uma página inteira para falar do Centro Popular de Cultura (30 de dezembro de 1961), de suas atividades e ideias, e se comprometeu a ajudar na luta de levar cultura ao povo. Dizia a matéria: "propõe-se $O$ Metropolitano e particularmente a Página de Arte, a divulgação das atividades do Centro Popular de Cultura, de modo a também contribuir e ajudar no esforço mais digno que os jovens têm em relação ao desenvolvimento cultural do país”.

Como de costume, no início de 1962, David Neves e Sérgio Augusto publicaram "Cinema: os melhores do ano" (6 de janeiro de 1962), em que sugeriam novamente duas listas dada a impossibilidade de conciliarem suas opiniões. ${ }^{10} \mathrm{~A}$ novidade dessa lista foi um comentário destinado ao cinema brasileiro, que não havia estado presente nas listas dos melhores filmes em anos anteriores. Isso foi resultado de um cinema novo, com produções cinematográficas vindas tanto da Bahia quanto do Rio de Janeiro com o filme Cinco vezes favela. ${ }^{11}$ Dizia David: "Estamos numa encruzilhada. Agora, basta trilhar o caminho certo." Em relação ao filme da Nouvelle Vague, Acossado, David Neves o colocava no topo da lista; já Sérgio Augusto o colocava em $6^{\circ}$ lugar. A partir dessa data os comentários sobre a Nouvelle Vague desapareceram da coluna de cinema, e o movimento francês não seria mais tema de artigos em $O$ Metropolitano. Sérgio Augusto ainda se concentraria em analisar alguns filmes estrangeiros, mas Carlos Diegues e David Neves se dedicariam cada vez mais ao cinema novo que despontava no Brasil. Lembramos que o ano de 1962 foi particularmente rico e de grande importância para a nossa cinematografia do ponto de vista da produção de filmes, em que se destacaram Os cafajestes de Ruy Guerra; $O$ assalto ao trem pagador de Roberto Farias; O pagador de promessas de Anselmo Duarte; $A$ grande 


\section{A Nouvelle Vague sob o ponto de vista do jornal O Metropolitano}

feira e Tocaia no asfalto, de Roberto Pires, e Cinco vezes favela, produção do CPC amplamente difundida nas páginas de $O$ Metropolitano. $\mathrm{O}$ cinema brasileiro ainda alcançou o reconhecimento internacional com a Palma de Ouro no Festival de Cannes para $O$ pagador de promessas ${ }^{12}$ e com a difusão das ideias e dos filmes do, agora, Cinema Novo.

O que podemos apreender das críticas escritas por David Neves, Carlos Diegues e Sérgio Augusto em O Metropolitano, neste percurso de 1959 a 1962, é que o interesse pelo movimento francês Nouvelle Vague foi sempre relativo. A Nouvelle Vague adquiriu importância por aquilo que ela podia contribuir para o desenvolvimento da nossa cinematografia, ou seja, pelo método de produção baseado no baixo orçamento e na renovação de linguagem, de que o filme $A$ cossado, do cineasta Jean-Luc Godard, era o exemplo maior. Os conteúdos dos filmes da Nouvelle Vague receberam fortes ataques justamente por não demonstrarem uma preocupação de caráter político e social, questões suscitadas pelo reflexo conjuntural da sociedade brasileira na época, caracterizada pelo nacionalismo e ao mesmo tempo pelo acirramento dos embates sociais.

Notas

1. Essa definição e distinção do tipo de nacionalismo desejado também está presente na argumentação dos isebianos. Ver Toledo (1997).

2. Essa deve ter sido uma decisão bastante difícil para a equipe de $O$ Metropolitano, uma vez que a intenção do jornal sempre foi a ampliação de sua capacidade de circulação. Um exemplo disso foi a "façanha”, termo usado pelo jornal, para propagandear o fato de a equipe ter conseguido, durante a cobertura do Congresso $\mathrm{Na}$ cional dos Estudantes em 1959, produzir uma tiragem de 640 mil exemplares em apenas uma semana (17 de julho de 1960).

3. Como exemplo podemos citar a cobertura da I Convenção Nacional da Crítica Cinematográfica, ocorrida entre os dias 12 e 15 de novembro de 1960 na cidade de São Paulo, em que o tema foi destaque na capa, com matéria ocupando a última página da edição do dia 27 de novembro de 1960.

4. David Neves, além de crítico de cinema, foi fotógrafo, montador, produtor e diretor de filmes como Memória de Helena (1969); Lúcia McCartney, uma garota de programa (1970); Muito prazer (1979); Flamengo paixão (1980); Luz del Fuego (1981). Carlos Diegues (Cacá Diegues) foi ativo participante do Centro Popular de Cultura e é cineasta com uma filmografia que atravessa os últimos 50 anos do cinema brasileiro, tendo dirigido filmes como Cinco vezes favela - $3^{\circ}$ episódio: Escola de samba, alegria de viver (1961); Ganga Zumba, rei dos Palmares (1963/4); A grande cidade (1965); Xica da Silva (1976); Bye-bye Brasil (1979); Dias melhores virão (1989); Orfeu (1998/9), entre outros. 
5. Desde 1996 Sérgio Augusto escreve para o jornal O Estado de S. Paulo.

6. O catálogo História do cinema francês 1895-1959 contou com textos produzidos por críticos de cinema, dos mais antigos aos mais jovens, entre eles Paulo Emílio Sales Gomes, Antonio Moniz Vianna, Francisco de Almeida Salles, José Lino Grünewald, Gustavo Dahl, Jean-Claude Bernardet e Rudá Andrade, apenas para citar alguns nomes. $\mathrm{O}$ artigo intitulado $L a$ Nouvelle Vague ficou a cargo de Nelson Dantas.

7. A palestra foi realizada pelo Pe. Guido Logger.

8. A lista de melhores do ano de 1960 de David Neves incluía: $1^{\circ}$ - Intriga internacional de A. Hitchcock; $2^{\circ}-$ Os espiões de $\mathrm{H}$. G. Clouzot; $3^{\circ}$-Ascensor para o cadafalso de Louis Malle; $4^{\circ}-$ Rio Bravo de Howard Hawks; $5^{\circ}$ - Hiroshima, meu amor de Alain Resnais; $6^{\circ}$-Os primos de Claude Chabrol; $7^{\circ}$ - Abismo de um sonho de Federico Fellini; $8^{\circ}-A$ doce vida de Federico Fellini.

9. A lista de melhores do ano de 1960 de Sérgio Augusto incluía: $1^{\circ}$ - Rio Bravo de Howard Hawks; $2^{\circ}-A$ doce vida de Federico Fellini; $3^{\circ}$-Homens em fúria de Robert Wise; $4^{\circ}-$ Abismo de um sonho de Federico Fellini; $5^{\circ}$ - Quanto mais quente melhor de Billy Wilder; $6^{\circ}-$ Marcha de heróis de John Ford; $7^{\circ}$ - Intriga internacional de A. Hitchcock; $8^{\circ}-U m$ broto para o verão de Edouard Molinaro; $9^{\circ}$ - De crápula a herói de Roberto Rosselini; $10^{\circ}$ - Sem saída de Seth Holt.

Referências bibliográficas

AUGUSTO, Sérgio. Clair na Academia. $O$ Metropolitano, 17 de julho de 1960.
Menção honrosa: $11^{\circ}$ - Hiroshima, meu amor de Alain Resnais.

10. Lista de David Neves: $1^{\circ}-$ Acossado de Jean-Luc Godard; $2^{\circ}-A$ aventura de Michelangelo Antonioni; $3^{\circ}-A$ um passo $d a$ liberdade de Jacques Becker; $4^{\mathrm{O}}-\mathrm{O}$ sol por testemunha de René Clément; $5^{\circ}-$ Rocco e seus irmãos de Luchino Visconti; $6^{\circ}-U m a$ vida em pecado de Irving Lerner; $7^{\circ}-A$ adolescente de Luis Buñuel; $8^{\circ}-A$ viagem de balão de Albert Lamorisse; $9^{\circ}$ - Psicose de Alfred Hitchcock; $10^{\circ}-$ Amor livre de Jacques Doniol-Valcroze.

Lista de Sérgio Augusto: $1^{\circ}$ - Uma vida em pecado de Irving Lerner; $2^{\circ}-$ Rocco e seus irmãos de Luchino Visconti; $3^{\circ}-O$ sol por testemunha de René Clément; $4^{\circ}-$ Cilada mortífera de Irving Lerner; $5^{\circ}-A$ um passo da liberdade de Jacques Becker; $6^{\circ}$ Acossado de Jean-Luc Godard; $7^{\circ}-A$ aventura de Michelangelo Antonioni; $8^{\circ}$ Os 1000 olhos do Dr. Mabuse de Fritz Lang; $9^{\circ}$ - Psicose de Alfred Hitchcock; $10^{\circ}$ Audazes e malditos de John Ford

11. Filme de episódios produzido pelo CPC (Centro Popular de Cultura) composto por cinco curtas-metragens: Couro de gato de Joaquim Pedro de Andrade; Zé da Cachorra de Miguel Borges; Escola de Samba Alegria de Viver de Cacá Diegues; Pedreira de São Diogo de Leon Hirzchmann; Um favelado de Marcos Farias.

12. O pagador de promessas foi selecionado como representante do Brasil no Festival de Cannes, concorrendo com Os cafajestes de Ruy Guerra. 
- Resposta ao leitor. O Metropolitano, 2 de outubro de 1960.

. Cinema moderno e Nouvelle Vague. $O$ Metropolitano, 20 de novembro de 1960.

O melhor do cinema. O Metropolitano, 22 de janeiro de 1961.

Plein soleil: um novo Clément. $O$ Metropolitano, 12 de março de 1961.

Ainda Plein de Soleil. O Metropolitano, 26 de março de 1961.

e NEVES, David E. Cinema. Os melhores do ano. $O$ Metropolitano, 15 de janeiro de 1961.

$-\mathrm{e}-$ Cinema. Os melhores do ano. O Metropolitano, 6 de janeiro de 1962.

BRUM, Alessandra. Hiroshima, mon amour e a recepção da crítica no Brasil. Tese de doutorado, Instituto de Artes da Unicamp, Programa de Pós-graduação em Multimeios, Campinas, agosto de 2009.

BUENO, Zuleika de Paula. Bye Bye Brasil: a trajetória de Carlos Diegues e do Cinema Brasileiro (1960-1979). Dissertação de mestrado, Departamento de Sociologia do Instituto de Filosofia e Ciências Humanas da Universidade Estadual de Campinas, 2000.

CARVALHO, Maria do Socorro Silva. $A$ nova onda baiana. Cinema na Bahia 1958/ 1962. Salvador: EDUFBA, 2002.

COSTA, Flávio Moreira da (org.). Cinema Moderno. Cinema Novo. Rio de Janeiro: José Álvaro Editor S.A., 1966.

CINEMATECA do Museu de Arte Moderna do Rio de Janeiro. História do cinema francês - 1895-1959. Catálogo da II Mostra internacional de arte cinematográfica, MAM/RJ, Rio de Janeiro, 1959.

DIEGUES, Carlos. Nouvelle Vague. O Metropolitano, 27 de setembro de 1959.
- Nouvelle Vague. O Metropolitano, 14 de agosto de 1960.

-Perspectivas para o cinema brasileiro. O Metropolitano, 2 de julho de 1960.

e NEVES, David E. Roteiro para a história do cinema. O Metropolitano, $12 \mathrm{de}$ junho de 1960.

GRÜNEWALD, José Lino. Cinema 1960. Fornal de Letras, jan/fev.1961.

. Marienbad - inauguração de uma linguagem. Fornal de Letras, jul. 1962.

MARIE, Michel. La Nouvelle Vague. Une école artistique. Paris: Nathan-Université, 1998.

NEVES, David E. Telégrafo visual. Crítica amável de cinema. Org. Carlos Augusto Calil. São Paulo: Editora 34, 2004.

-Jean Renoir e a Nouvelle Vague. $O$ Metropolitano, 11 de outubro de 1959.

Retrospecto dos melhores de 1959. O Metropolitano, 10 de janeiro de 1960.

. Aspectos da II Jornada dos cineclubes. $O$ Metropolitano, 31 de janeiro de 1960.

julho de 1960.

. Hiroshima-Nevers: um itinerário. O Metropolitano, 07 de agosto de 1960.

. Um filme e um conflito. O Metropolitano, 21 de maio de 1961.

. Os primitivos da Nouvelle Vague. O Metropolitano, 18 de novembro de 1960.

ORTIZ, Renato. Cultura brasileira e identidade nacional. São Paulo: Brasiliense, 2006.

SALLES, Francisco Luiz de Almeida. $\mathrm{Ci}$ nema e verdade: Marilyn, Buñuel, etc. Por um escritor de cinema. Org. Flora Christina Bender e Ilka Brunhilde Laurito. São Pau- 
lo: Cia. das Letras; Cinemateca Brasileira; Fundação do Cinema Brasileiro, 1988.

TOLEDO, Caio de Navarro de. ISEB: fábrica de sonhos. São Paulo: Ática, 1977.
VIANY, Alex. O processo do Cinema Novo. Rio de Janeiro: Aeroplano, 1999.

XAVIER, Ismail. O cinema brasileiro moderno. São Paulo: Paz e Terra, 2001.

\section{Resumo}

Este artigo toma como objeto de reflexão os textos da coluna de cinema de $O$ Metropolitano, órgão oficial da União Metropolitana dos Estudantes, sobre o movimento cinematográfico francês Nouvelle Vague à luz das posições políticas e ideológicas do jornal. Concentramos nossa análise nas críticas escritas principalmente por Cacá Diegues, David Neves e Sérgio Augusto no período que se estende de 1959, quando as primeiras notícias sobre a Nouvelle Vague começaram a despontar no Brasil, até o ano de 1962, quando o Cinema Novo se firmou como movimento.

Palavras-chave: O Metropolitano; Nouvelle Vague; crítica de cinema.

\section{Absctrat}

This article analyses the movie reviews of $O$ Metropolitano, published by the Metropolitan Students Union of Rio de Janeiro, concerning the French cinematographic movement Nouvelle Vague in the light of the newspaper's political and ideological positions. We focuse on the critics by Carlos Diegues, David Neves and Sérgio Augusto in the period going from 1959, when the first news about the Nouvelle Vague began to emerge in Brazil, until 1962, when Cinema Novo was established as a movement.

Keywords: O Metropolitano; Nouvelle Vague; film criticism.

\section{Résumé}

Cet article prend comme objet de réflexion les critiques cinématographiques d'O Metropolitano, publié par l'Union Métropolitaine des Étudiants à Rio de Janeiro, sur le mouvement de la Nouvelle Vague à la lumière des positions politiques et idéologiques du journal. Nous concentrons notre analyse sur les critiques de cinéma écrites par Carlos Diegues, David Neves et Sérgio Augusto dans la période qui s'étend de 1959, lorsque les premières nouvelles à propos de la Nouvelle Vague ont commencé à émerger au Brésil, jusqu'en 1962, lorsque le Cinema Novo s'est firmé comme mouvement. Mots-clés: O Metropolitano; Nouvelle Vague; critique de cinéma. 